\title{
Deterioro de las cerámicas y vidrieras del edificio del Ayuntamento de San Sebastián
}

\author{
J.I. ALAVA, J.M. VALERO, R. SOLOZABAL y G. ORTIZ DE URBINA \\ INASMET. Centro Tecnológico de Materiales. Camino Portuetxe 12. 20009 San Sebastián
}

\begin{abstract}
Se han estudiado las cerámicas y las vidrieras que sirven de adorno al edificio del Ayuntamiento de San Sebastián, considerado monumento nacional, y que ha sido objeto de una reciente restauración. Se ha observado que las cerámicas presentan un alto grado de deterioro de la capa de esmalte superficial, y se ha estudiado el posible origen de este deterioro. Se concluye que el deterioro es de origen fisicoquímico, no pudiendo este ser de origen biológico debido a las elevadas concentraciones de metales pesados que lixivian de dicho esmalte y que impiden el crecimiento de microorganismos. Se ha observado asimismo que las vidrieras presentan un aumento de ciertos elementos y pérdida de otros en los primeros $\mu \mathrm{m}$ de profundidad.

Palabras clave: Cerámica, Vidriera, Deterioro, Metales, Microscopía

Deterioration of ceramics and stained glasses of the city hall building of San Sebastian

The ornamental ceramics and stained-glass windows of the City Hall building of San Sebastian have been studied. This building is a national monument which has been restored recently. It has been studied the origin of the observed high deterioration degree of the superficial enamel of these ceramics. We have concluded that the deterioration has a physicochemical origin. The biological origin has been excluded because of the high concentration of heavy metals leached from the enamel which avoid the growth of microorganisms. It has also been observed an increase of some elements and the loss of another ones in the first $\mu \mathrm{m}$ of depth.
\end{abstract}

Keywords: Ceramic, Stained-Glass, Deterioration, Metals, Microscopy

\section{INTRODUCCIÓN}

El edificio del Ayuntamiento de San Sebastián es una de las más importantes obras arquitectónicas que adornan la ciudad de San Sebastián. Tiene una antigüedad de más de un siglo, ya que fue construido en 1887 por los arquitectos Morales de los Ríos y Aladrén, teniendo consideración actualmente de monumento nacional. Está construido principalmente en piedra arenisca de las canteras próximas de Igeldo y Ulia, aunque ciertas zonas del edificio fueron acabadas con piedra caliza de Motrico. Finalmente este edificio queda rematado por medio de cerámicas en todas sus fachadas y vidrieras coloreadas en su parte superior.

En 1.995 se acomete la restauración del mismo por la empresa Tecpropasa Euskadi (TEUSA), quien en coordinación con INASMET se encarga de realizar la obra de restauración. Fruto de esta restauración es este trabajo sobre el estado de deterioro de las cerámicas y vidrieras del edificio.

\section{MATERIALES Y MÉTODOS}

\subsection{Estudio de las cerámicas}

Las cerámicas del edificio fueron realizadas por la empresa Pickman y Compañía China Opaca de Sevilla, como puede observarse en la figura 1, en la que se puede ver el sello que dicha empresa imprimía en cada una de las cerámicas utiliza-

das en este edificio. Las cerámicas diseminadas por todo el edificio presentan diversos diseños diferentes, uno de los cuales puede observarse en la figura 2.

Las técnicas utilizadas para el estudio de las cerámicas consistieron en una microscopía óptica, una lixiviación del esmalte, un análisis elemental, ecotoxicidad y análisis microbiológico y microscopía electrónica de barrido (SEM) con microsonda EDS.

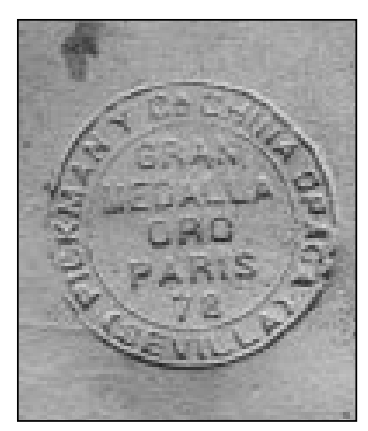

Figura 1. Se puede observar el emblema impreso por la compañía sobre las cerámica utilizadas en el edificio.

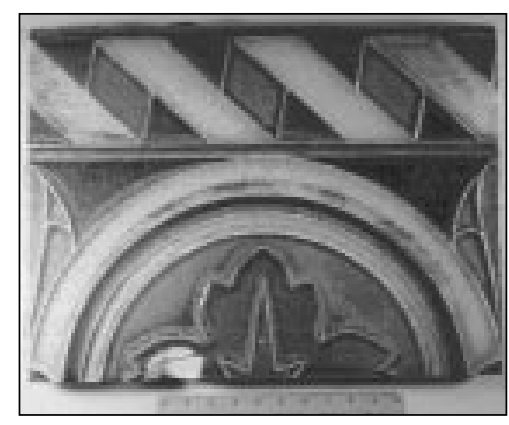

Figura 2. Ejemplo de cerámica. Se puede observar la cantidad de materia orgánica y suciedad acumulada sobre la misma. 
El análisis microbiológico (1) de las muestras se realizó poniendo en contacto con un tampón fosfato, la cara superficial de la cerámica, resuspendiendo de este modo las sustancias acumuladas sobre la misma. De esta suspensión, realizada homogéneamente en varias zonas de la cerámica, se inocularon alicuotas en diferentes medios de cultivo para bacterias aerobias (agar TPC), hongos (agar Sabouraud Dextrosa), levaduras (agar malta), actinomicetos (Actinomycetes Isolation Agar), Pseudomonadaceas (agar King A), anaerobios mesófilos (Brewer Anaerobic Agar), algas clorofíceas (Caldo Detmer), algas diatomeas (Caldo Lewin) y cianobacterias (BG11 for blue green algae). Se prepararon diluciones decimales y se inoculó en cada placa de agar o tubo de caldo $1 \mathrm{ml}$ de la suspensión original o de sus diluciones. El ensayo se realizó por triplicado. Los recuentos de cada grupo de microorganismos se realizaron en los tiempos adecuados para cada grupo en concreto, quedando expresados para recuentos en placa como u.f.c. (unidades formadoras de colonias) y para recuentos en tubo como N.M.P. (Número más probable).

La lixiviación del esmalte fue realizada extrayendo la capa superior de esmalte de la vidriera y poniendo una cantidad de 4 gramos del polvo extraído en contacto con 16 veces su peso en agua y cuatro veces su peso en acético $0,1 \mathrm{~N}$, de forma análoga al ensayo de lixiviación EP (Extraction Procedure) (2), con agitación continua durante un período de 96 horas. Este procedimiento fue el empleado ya que simula el efecto de lavado de un material expuesto en el exterior por el agua de lluvia, de carácter levemente ácido.

Del lixiviado obtenido se realizó un análisis elemental mediante espectrometría de emisión con plasma acoplado por inducción, que tiene como objetivo conocer los elementos y la concentración en que estos están presentes en una muestra. Los elementos analizados fueron los siguientes: $\mathrm{Al}, \mathrm{As}, \mathrm{Zn}, \mathrm{Ni}$, $\mathrm{Cr}, \mathrm{Fe}, \mathrm{Mg}, \mathrm{Mn}, \mathrm{Mo}, \mathrm{Pb}, \mathrm{Be}, \mathrm{Cu}, \mathrm{Ca}, \mathrm{Ba}, \mathrm{Cd}, \mathrm{Sb}$ y $\mathrm{Co}$.

Asimismo, se midió en el lixiviado la ecotoxicidad empleando cepas bioluminiscentes de Photobacterium phosphoreum. Este ensayo consiste en poner diferentes concentraciones de la muestra en contacto con el microorganismo. Esta bacteria marina del género de las vibrionáceas posee un sistema enzimático luciferina-luciferasa, que le da la capacidad de emitir luz. La emisión de luz está directamente relacionada con el estado metabólico de la célula, por lo que se puede utilizar para medir la toxicidad de una sustancia. La ecotoxicidad de una sustancia se expresa como la cantidad de la misma que produce una disminución de la luz emitida del 50\% (EC50).

La microscopía óptica sobre la cerámica se realizó utilizando una técnica de microscopía óptica de reflexión con módulo polarización, mediante un equipo MeF. (Reichert-Jung), tras embutir la pieza en resina epoxi a vacío.

Para el estudio de las cerámicas se empleó asimismo la microscopía electrónica de barrido (SEM) con microsonda EDS (espectroscopía de dispersión de energías) $(3,4)$. Para ello se realizó un barrido lineal, sintonizando el detector con la energía de cada elemento que se estaba buscando, logrando así conocer la distribución de los principales elementos en un corte tangencial, incluyendo el esmalte de la cerámica y el soporte subyacente.

\subsection{Estudio de las vidrieras}

La muestra de vidriera se tomó de la zona de la cúpula superior del edificio. Esta muestra se tomó de una zona en avanzado estado de deterioro, que impedía la recuperación de la misma, y que por lo tanto debía ser sustituida. El deterioro de la vidriera en esta zona se supone originado por roturas causadas por esfuerzos mecánicos, ya que se trata de una zona habitualmente batida por el viento.

Para el estudio de las vidrieras se empleó la microscopía electrónica de barrido (SEM) con microsonda EDS (espectroscopía de dispersión de energías). Para ello se realizó un barrido lineal, sintonizando el detector con la energía de cada elemento que se estaba buscando, logrando así conocer la distribución de los principales elementos en un corte tangencial, desde el exterior de la vidriera hasta el interior a una profundidad de aproximadamente $150 \mu \mathrm{m}$.

\section{RESULTADOS}

\subsection{Estudio del deterioro de las cerámicas}

El estudio de las cerámicas se encaminó en un primer momento a determinar la posibilidad de la existencia de un biodeterioro (5) por microorganismos de las mismas. Para conocer este punto se decidió realizar un análisis microbiológico de la cerámica, cuyos resultados se reflejan en la tabla I.

TABLA I.

ANÁLISIS MICROBIOLÓGICO DE LA SUPERFICIE DE LA CERÁMICA. ÁREA MUESTREADA $39 \mathrm{CM}^{2}$.

\begin{tabular}{|l|c|}
\hline Grupo de microorganismos & Recuento \\
\hline Bacterias aerobias & $3.5 \times 10^{2}$ u.f.c. $/ 100 \mathrm{~cm}^{2}$ \\
\hline Bacterias anaerobias & 0 u.f.c. $/ 100 \mathrm{~cm}^{2}$ \\
\hline Hongos & $5 \times 10^{1}$ u.f.c. $/ 100 \mathrm{~cm}^{2}$ \\
\hline Levaduras & $2.3 \times 10^{2}$ u.f.c. $/ 100 \mathrm{~cm}^{2}$ \\
\hline Actinomicetos & $6.6 \times 10^{1}$ u.f.c. $/ 100 \mathrm{~cm}^{2}$ \\
\hline Pseudomonadaceas & $1.5 \times 10^{2}$ u.f.c. $/ 100 \mathrm{~cm}^{2}$ \\
\hline Cloroficeas & 0 N.M.P. $/ 100 \mathrm{~cm}^{2}$ \\
\hline Diatomeas & 0 N.M.P. $/ 100 \mathrm{~cm}^{2}$ \\
\hline Cianobacterias & 0 N.M.P. $/ 100 \mathrm{~cm}^{2}$ \\
\hline
\end{tabular}

Como se puede observar, los recuentos son extremadamente bajos en todos los grupos de microorganismos, en comparación con los valores habitualmente encontrados en otros tipos de materiales pétreos (6), en los que se alcanzan recuentos superiores en varios órdenes de magnitud.

Una vez analizados estos datos, se decidió investigar el porqué de valores tan bajos de microorganismos, planteando como primera hipótesis la presencia de metales pesados tóxicos para los microorganismos en el esmalte superior de las cerámicas. Para probar este extremo, se realizó una lixiviación del esmalte de la cerámica en medio ácido, simulando aceleradamente las condiciones de lavado por agua de lluvia ligeramente ácida.

Resultado de dicha lixiviación es el análisis elemental que se observa en la tabla II, en el que se investigaron 17 elementos diferentes, algunos de ellos habitualmente utilizados en la formulación de esmaltes cerámicos antiguos. 
TABLA II. ANÁLISIS ELEMENTAL DEL LIXIVIADO DE LA CERÁMICA

\begin{tabular}{|c|c|c|c|}
\hline Elemento & Concentración (mg/l) & Elemento & Concentración (mg/l) \\
\hline $\mathrm{Al}$ & 45,9 & $\mathrm{As}$ & $<0,2$ \\
\hline $\mathrm{Zn}$ & 5,04 & $\mathrm{Ni}$ & 64,6 \\
\hline $\mathrm{Cr}$ & 0,1 & $\mathrm{Fe}$ & 244 \\
\hline $\mathrm{Mg}$ & 8,2 & $\mathrm{Mn}$ & 0,53 \\
\hline $\mathrm{Mo}$ & $<0,05$ & $\mathrm{~Pb}$ & 42 \\
\hline $\mathrm{Be}$ & $<0,05$ & $\mathrm{Cu}$ & 4,24 \\
\hline $\mathrm{Ca}$ & 90,2 & $\mathrm{Ba}$ & 0,1 \\
\hline $\mathrm{Cd}$ & $<0,05$ & $\mathrm{Sb}$ & $<2$ \\
\hline $\mathrm{Co}$ & 116 & \multicolumn{2}{|l}{} \\
\cline { 2 - 4 } & \multicolumn{2}{|l}{} &
\end{tabular}

Estos datos de análisis demuestran la hipótesis de la presencia de elevadas concentraciones de metales en el lixiviado de la cerámica. Para conocer el potencial tóxico de dicho lixiviado se realizó un estudio de ecotoxicidad, obteniendo un valor de EC50 de $6214 \mathrm{mg}$ lixiviado/1, lo que muestra que el lixiviado posee una elevada toxicidad.

De los resultados anteriores se puede deducir que el proceso de deterioro que sufren las cerámicas no es debido al biodeterioro por microorganismos. Para estudiar otras posibles causas de deterioro se decidió realizar una microscopía óptica de la cerámica. En la figura 3 se puede observar un detalle de la capa superficial de esmalte de la cerámica.

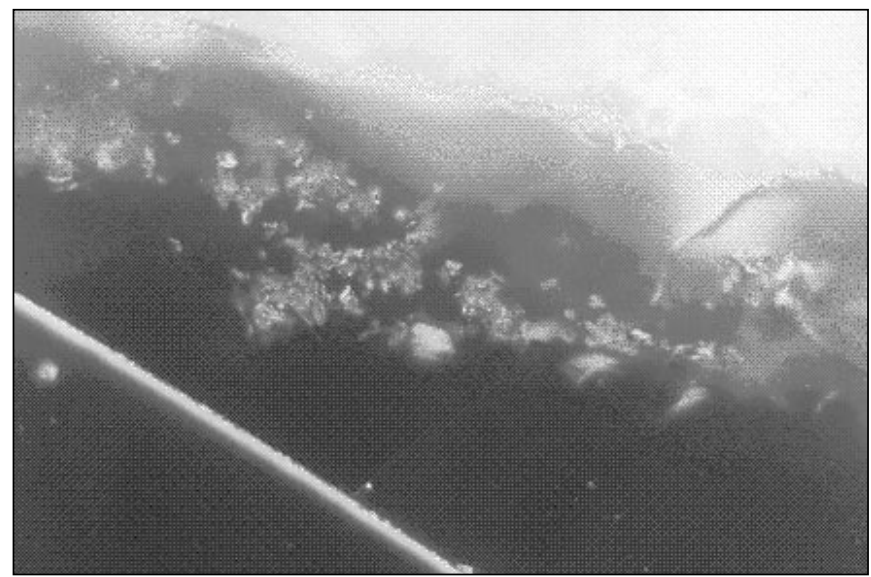

Figura 3. Microscopía óptica (aumentado x 500) de la capa superficial de esmalte de la cerámica, en la que se puede observar la recristalización.

En la tabla III se puede observar el resultado del análisis EDS de la capa de esmalte superficial y del soporte subyacente.

\subsection{Estudio del deterioro de la vidriera}

Para el estudio del deterioro de las vidrieras se realizó una microscopía electrónica de barrido, ya que esta técnica nos permite realizar simultáneamente el análisis y la observación de la muestra.
TABLA III.

ELEMENTOS PRESENTES EN LA CAPA DE ESMALTE Y EL SOPORTE DE LA CERÁMICA

\begin{tabular}{|c|c|c|}
\hline Elemento & Soporte & Esmalte \\
\hline $\mathrm{SiO}_{2}$ & $13,621 \%$ & $19,848 \%$ \\
\hline $\mathrm{Al}_{2} \mathrm{O}_{3}$ & $1,347 \%$ & $1,920 \%$ \\
\hline $\mathrm{SO}_{3}$ & $0,704 \%$ & $0,574 \%$ \\
\hline $\mathrm{Cl}_{2} \mathrm{O}$ & $0,618 \%$ & $0,086 \%$ \\
\hline $\mathrm{K}_{2} \mathrm{O}$ & $0,973 \%$ & $1,166 \%$ \\
\hline $\mathrm{CaO}$ & $1,223 \%$ & $4,108 \%$ \\
\hline $\mathrm{Fe}_{2} \mathrm{O}_{3}$ & $4,471 \%$ & $0,170 \%$ \\
\hline $\mathrm{ZnO}$ & $0,106 \%$ & $0,093 \%$ \\
\hline $\mathrm{PbO}$ & $3,092 \%$ & $14,409 \%$ \\
\hline
\end{tabular}

Del análisis de la vidriera se puede obtener que los principales elementos presentes en la misma y que poseen una distribución diferencial son el azufre, el silicio y el calcio. En la tabla III se puede observar los elementos encontrados (en porcentaje en peso de óxidos) en una zona puntual de la vidriera:

En las siguientes figuras se puede observar su distribución a lo largo del corte transversal hasta una profundidad de $150 \mu \mathrm{m}$ (Figuras 4 y 5).

\section{CONCLUSIONES}

\subsection{Cerámica}

De los datos obtenidos de los análisis realizados a la cerámica (análisis microbiológico, análisis elemental y ecotoxicidad del lixiviado), se puede concluir que el deterioro de la misma

TABLA IV.

ELEMENTOS PRESENTES EN LA VIDRIERA

\begin{tabular}{|c|c|}
\hline Elemento & Proporción (\%) \\
\hline $\mathrm{SiO}_{2}$ & 68,19 \\
\hline $\mathrm{Al}_{2} \mathrm{O}_{3}$ & 0,84 \\
\hline $\mathrm{Na}_{2} \mathrm{O}$ & 14,60 \\
\hline $\mathrm{CaO}$ & 15,44 \\
\hline $\mathrm{K}_{2} \mathrm{O}$ & 0,35 \\
\hline $\mathrm{Fe}_{2} \mathrm{O}_{3}$ & 0,42 \\
\hline $\mathrm{Cr}_{2} \mathrm{O}_{3}$ & 0,058 \\
\hline $\mathrm{PbO}$ & 0,10 \\
\hline $\mathrm{P}_{2} \mathrm{O}_{5}$ & $<$ \\
\hline $\mathrm{MnO}$ & $<$ \\
\hline $\mathrm{MgO}$ & $<$ \\
\hline $\mathrm{CoO}$ & $<$ \\
\hline $\mathrm{CuO}$ & $<$ \\
\hline
\end{tabular}


tiene un origen fisicoquímico, por los bajos recuentos de poblaciones encontrados, y por la alta toxicidad debida a los metales que posee.

Por otro lado, de la observación visual y por microscopía óptica de la cerámica se puede deducir que el deterioro observado tiene varias causas. Por un lado la lixiviación continua que sufre la capa superior de esmalte por el agua de lluvia, que produce un efecto de pérdida de metales en la misma. Otra causa la encontramos en fenómenos de recristalización superficial. Finalmente, el deterioro se debe también a los ciclos de frío y calor y la presión que sobre las cerámicas ejercen las adyacentes. Este fenómeno queda patente por la distribución de las grietas del esmalte en la cerámica (7).

\subsection{Vidriera}

Las principales características de la vidriera son un contenido en sílice alto $(68.19 \%)$ y una predominancia de iones sodio sobre los iones potasio, lo que lo convierte en un vidrio sódico-cálcico. Estas características confieren al vidrio una buena estabilidad. Cabe destacar asimismo la práctica ausencia de iones magnesio.

Según la clasificación de Bettembourg (10) se trataría de un vidrio estable por presentar una relación $\mathrm{Si} / \mathrm{R}_{2}$ superior a 3 (4.56) y un valor de $\mathrm{R}_{2}$ inferior al 20\% (14.95\%).

De la observación realizada mediante el barrido lineal con la microsonda EDS se puede destacar una ligera pérdida de óxidos formadores en la zona superficial (primeros micrometros). Sin embargo, el detalle diferencial más destacable es la distribución de calcio y azufre. Se puede observar un incremento importante de ambos elementos en la zona superficial, lo que indica la posible formación de una costra superficial en la que el componente principal podría ser sulfato de calcio (posiblemente en forma de yeso).

El aumento en la presencia de calcio y la aparición del azufre parecen ser debidos a la contaminación atmosférica, especialmente en el caso del azufre, cuyo origen más plausible sería el $\mathrm{SO}_{2}$ ambiental (8). Cabe destacar que el edificio del Ayuntamiento de San Sebastián se halla inmerso en pleno centro urbano, soportando en sus cercanías un intenso tráfico rodado.

Como se puede observar la variación de estos elementos alcanza una profundidad de hasta 100 micrómetros, siendo esta profundidad bastante elevada para una vidriera de poco más de cien años de antigüedad, si la comparamos con los resultados obtenidos de trabajos semejantes sobre vidrieras medievales con una antigüedad mucho mayor.

\section{BIBLIOGRAFIA}

1. I.C.R. Instituto Centrale per il Restauro. $<<$ Raccomandazioni NORMAL 9/88 Microflora autotrofa ed eterotrofa: tecniche di isolamento in coltura $>$. C.N.R. Centri di studio de Milano e Roma cause de deperimento e sui metodi di conservazione delle opere d'arte. (1988)

2. Método 1 OEP. B.O.E. $\mathrm{n}^{\circ} 270$ de 10 de noviembre de 1989 . Orden de 13 de octubre de 1989 por la que se determinan los métodos de caracterización de los residuos tóxicos y peligrosos.

3. J. Sterpenich, L. Leforestier y G. Libourel. $<<$ Les vitraux Médiévaux: un modè-

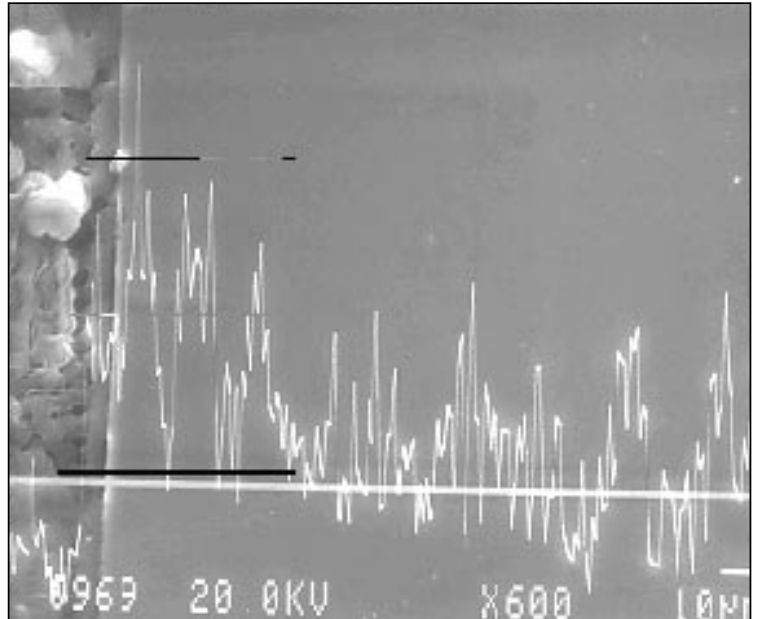

Figura 4. Microscopía electrónica (aumento x 600) en el que se observa la distribución espacial de $S$ desde el exterior hacia el interior.

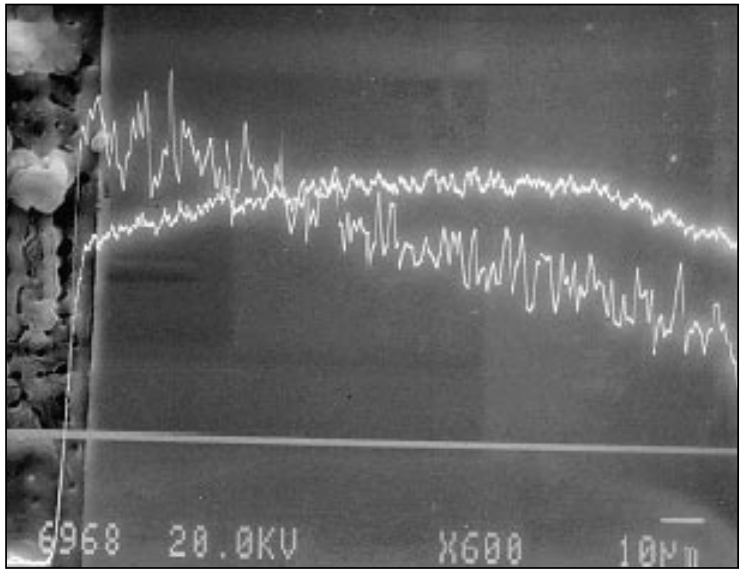

Figura 5. Microscopía electrónica (aumento x 600) en el que se observa la distribución espacial de Si (trazo ascendente hacia el interior) y Ca (trazo descendente hacia el interior) desde el exterior hacia el interior.

le pour le vieillissement des déchets vitrifiés >>. CNRS et Université de Nancy.

4. B.K. Zoitos \& D.E. Clark. $<<$ Role of surface layers in the leaching behaviour of glass $>>$. Materials stability and Environmental Degradation. M.R.S. 125 169-176. (1988)

5. J.M. Muñoz Cebrián. « Biotecnología de los materiales. Introducción a la deterioración y degradación biológica de los materiales de interés tecnológico $>>$. C.E.D.E.X. M21. (1991).

6. F.J. Lewis, E. May, \& A.F. Bravery. $<<$ Isolation and enumeration of autotrophic and heterotrophic bacteria from decayed stone $>>$. Proceedings of the 5 th International Congress on Deterioration and Conservation of Stone. Vol 2. G. Felix Ed, Presses Polytechniques Romandes, Lausanne pp 633-641 (1985).

7. S.W. Freiman. $<<$ Environmentally enhanced fracture of ceramics $>>$. Materials stability and Environmental Degradation. M.R.S., 205-215 (1988).

8. F.J. Leon Vallejo. $\ll$ Análisis del ensuciamiento a causa de la contaminación atmosférica de fachadas con revestimiento petreo de edificios de Valladolid $\gg$. Tesis Doctoral, Facultad de Arquitectura, Universidad de Valladolid 1988.

9. J.M. Fernandez Navarro. $<<$ Procesos de alteración de las vidrieras medievales. Estudio y tratamientos de protección $>>$. Materiales de Construcción. Vol $46 \mathrm{n}^{\circ}$ 242-243, pp 137-157. (1996)

10. J.M. Bettembourg. $<<$ Composition et alteration des verres de vitraux anciens $>>$. Verres et Réfract. 30. 36-42 (1976). 